\title{
No impact signatures in Earth's oldest rocks from Acasta Gneiss Complex, Canada
}

\author{
AKIRA ISHIKAWA ${ }^{1,2}$, KeIKO KOSHIDA ${ }^{3}$, KATSUHIKO \\ SUZUKI $^{2}$, TETSUYA YOKOYAMA ${ }^{1}$, TSUYOSHI KOMIYA ${ }^{3}$ \\ ${ }^{1}$ Dept. of Earth Planet. Sci., Tokyo Institute of Technology, \\ Ookayama, Tokyo 152-8551, Japan \\ ${ }^{2}$ Japan Agency for Marine-Earth Science and Technology, \\ Natsushima-cho, Yokosuka 237-0061, Japan \\ ${ }^{3}$ Dept. of Earth Science and Astronomy, The University of \\ Tokyo, Meguro, Tokyo 153-8902, Japan
}

A recent petrogenetic modelling suggests that the Earth's oldest evolved rocks, the $4.02 \mathrm{Ga}$ Idiwhaa tonalitic gneisses of the Acasta Gneiss Complex, Canada, represent the predominant felsic crust at that time generated by impact melting of Hadean mafic crust. We test this hypothesis by investigating abundances of highly siderophile elements (HSEs) and Re-Os isotope systematics for the Idiwhaa tonalitic gneisses. These tracers are considered to be sensitive for involvement of extraterrestrial components and relatively immune to secondary alteration. In addition, a series of leastaltered amphibolites showing near chondritic patterns for incompatible trace elements were also examined since they are considered to preserve pre-metamorphic compositions of basaltic crust derived from Hadean mantle.

The preservation of Hadean HSE signatures in these rocks are supported by whole-rock Re-Os isotope data; the leastaltered amphibolites yield an errorchron with an age of 4318 $\pm 226 \mathrm{Ma}(\mathrm{MSWD}=390)$, and extremely radiogenic ${ }^{187} \mathrm{Os}$ ( $>94 \%$ of total Os) in Idiwhaa tonalites also provides a weighted mean ${ }^{187} \mathrm{Re}-{ }^{187} \mathrm{Os}$ model age of $\sim 4.0 \mathrm{Ga}$, consistent with the U-Pb ages of zircon. Regarding HSE abundances, both amphibolites and tonalites display strongly fractionated HSE patterns. Os, Ir and Ru concentrations in amphibolites are low with chondrite-normalizing values ranging from $10^{-3}$ to $10^{-5}$ level, and Idiwhaa tonalites contain much lower Os, Ir and $\mathrm{Ru}$ that are in the very low parts per trillion range. These data show no contribution of the meteoritic components to the generation of Idiwhaa tonalites, and lend no support to the hypothesis of impact melting. Moreover, the fact that the amphibolites display coherent HSE signatures similar to those in modern basalts indicates that the protoliths were derived from source mantle that already had acquired present-day mantle like HSE abundances. This tentatively suggests that late accretion components boosted the convecting mantle HSE inventory after core separation in the early Hadean, and that the impact flux from the end of Hadean to early Archean was not sufficient to completely obliterate preexisting crust. 